\title{
EFFECTS OF VITAMIN AND HORMONE TREATMENT ON SENILE PATIENTS
}

BY

\author{
P. E. VERNON and M. MCKINLAY
}

From the Laboratory for Clinical Research on Ageing at the Tooting Bec Hospital

(RECEIVED 20TH JUNE, 1946)

\section{Introduction}

THE changes brought about in mental and physical functions by ageing have been described by Korenchevsky (1942), in an article which points out the similarity between these senile symptoms and those resulting from vitamin deficiency and from deficiencies in the thyroid, adrenal, and sex glands. While treatment with vitamins and hormones has been shown to produce striking improvement in certain pathological conditions-according to the studies reviewed by this author-there seems to be very little direct evidence of their effects on the psychological capacities of senile patients. In one experiment extending over a year, in which forty patients were systematically treated with vitamins B and C, Stephenson, Penton, and Korenchevsky (1941) obtained improvements of about 10 to 30 per cent. over untreated controls on psychomotor tests such as tapping, dynamometer, and ergograph. In most cases distinct improvement was noted also in various clinical symptoms of senility. The patients, however, were normally kept on a diet low in vitamin content. Thus, it does not necessarily follow that similar improvement would result from giving extra vitamins to patients on a more adequate diet. This investigation also provided no information about mental functions, nor did it extend to the effects of hormones.

In preparation for a fuller inquiry, a large number of mental tests was studied by Halstead $(1943,1944)$, with a view to choosing a battery of tests which could be quickly applied to senile patients, readily understood by them, and of a suitable range of difficulty. A final set of some twenty tests, chosen by M. D. and H. J. Eysenck, Aubrey Lewis, William Stephenson, and P. E. Vernon, is described by Eysenck (1945), in an article which lists the average scores, standard deviations, reliabilities, and intercorrelations among 84 male senile patients at Tooting Bec Hospital. Halstead's and Eysenck's work show that mental abilities among such patients are considerably deteriorated, and that this deterioration chiefly affects tests involving abstract reasoning.

\section{The Present Investigation}

A detailed account of the investigation has been given, from the biochemical angle, by Richter (1946). During the first, or pre-treatment, phase (from January to July, 1943) all patients were tested individually in two sessions, averaging 55 minutes each, and retested some four months later. The performances on most of the tests were shown to be reasonably stable and reliable, and the averages of each patient's two sets of scores were used as the base line from which subsequent deviations were measured. The patients were classified into light, moderate, severe, and "anomalous" cases of senility, and then divided at random into treated and control groups-the psychologist, however, not being informed which patients were in which group. The " anomalous" patients had either severe physical and moderate or light mental symptoms, or the converse; but there were so few of them that they were eventually grouped with the severe cases.

During the first vitamin phase (August-December, 1943), the treated group was given small doses of vitamins $\mathrm{B}$ and $\mathrm{C}$, and the controls dummy tablets; and all patients were retested in two sessions. The pre-treatment tests had been given by M. D. Eysenck. Unfortunately she was unable to continue, and was succeeded by $\mathbf{M}$. McKinlay. Great care was taken, however, to ensure that the second psychologist followed the same procedures as the first, and during this phase they worked in co-operation. During the next phase (May-July, 1944) the treated patients were given larger doses. The onset of flying-bombs seriously disturbed the investigation, and a shortened battery of what appeared to be the most promising tests was applied, occupying only a single one-hour session. During the hormone phase (October-December, 1944), several groups, both of the vitamin-treated and untreated patients, were given large oral doses (75 mg. daily) of methyl testosterone for four weeks, and tested with the shortened battery in the third week. Apart from a few tests refused or unavoidably omitted, 84 patients (45 treated, 39 controls) took the two pre-treatment and first-vitamin tests. The numbers dropped, however, as the investigation proceeded, on account of patients leaving the hospital or dying. The second vitamin phase included 70 patients $(40$ treated, 30 controls), and the hormone phase 60 patients (26 hormone treated, 34 controls). The complete scheme of the trials is shown in Table I.

It might appear desirable to test the patients at more frequent intervals, and at the end of the whole experiment. But a psychological test is very different from, say, taking a temperature. Each repetition is different, owing to the effects of previous experience both of the test itself and of the whole testing situation. In all there were five applications, or eight sessions per patient. Had this number been increased, not only would memory and practice effects have seriously distorted the results, but also the more suspicious and irritable patients would have become unmanageable. While many of them enjoyed the testing as a break in the routine of their lives, others needed extremely tactful handling. A posttreatment test was rendered impossible by the closing down of the laboratory at the end of 1944. 


\section{Scoring of Changes in Test Performance}

Considerable difficulties were encountered in reaching a satisfactory technique for comparing pre-treatment and treatment performances. Simple subtraction of each patient's raw scores would be adequate with tests yielding normally distributed scores. But most tests gave highly skewed and irregular distributions, particularly the perseveration tests and the tests scored by time. Thus, a single patient whose time for " months backward" decreased from, say, 40 to 20 seconds, might wipe out small increases among half a dozen or more patients. A rough technique was to count merely the numbers of increases and decreases of score in each group, regardless of size. Though this overcame the difficulty of occasional excessive changes, and yielded some positive results, it was far from reliable since it failed to make use of all the available information. Contrasting the pre-treatment and first-vitamin tests, it was found that increases outweighed decreases among the treated-but not among the control-patients on the twelve chief psychological tests, though to a statistically insignificant extent:

\section{Increases, No change, Decreases,}

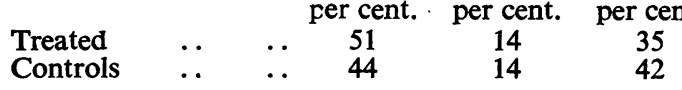

On the psychomotor tests, no such differences were found between the two groups of patients.

Eventually it was decided to convert the scores on all tests to a standard scale of $20-0$ points, where 20 always indicated the most favourable performance (e.g. most vocabulary words, least perseveration, etc.). Both the pre-treatment and first-vitamin scores were tabulated together, then the highest score in the table was called 20 , the next 19 , the next two 18 , the next four 17 , the next five 16, and so on; similarly the lowest score was called 0 , the next 1 , the next two 2 , and so on. If, say, four patients all made the same highest score, they were all called 19, and there were no 20 's or 18 's. If 13 patients refused a test, they were all called 3 , and there were no 0's, 1's, 2's, or 4's for that test. These scaled scores for all tests had approximately the same mean of 10 , and the same standard deviation of 4 though with slight variations because of the numerous " ties" just mentioned. Ideally, of course, the scaling should have been done on the basis of the scores of a much larger group than 168 (i.e. 2 times 84). With such scores the units can be taken as equivalent throughout the scale. One patient's time on the "matrix test " might alter from 16 to 10 minutes, another from 6 to 4 minutes. These times correspond to scaled scores of $5,9,15$, and 19 respectively, and so can be regarded as equivalent improvements. Any increases or decreases on different tests are also directly comparable. Moreover, the same conversion tables could be used for scaling the scores obtained at the second-vitamin and the hormone retests.

In presenting the results of the investigation, all we shall need are the differences in mean increases or decreases over the pre-treatment scores between the treated and the corresponding control groups, together with some indication of the statistical significance of such differences. For example, the figure -0.27 in Table II for the matrix test at the first-vitamin retests of light + moderate cases was obtained as follows:

\begin{tabular}{|c|c|c|c|}
\hline & $\begin{array}{l}\text { Pre- } \\
\text { treat- } \\
\text { ment } \\
\text { test }\end{array}$ & $\begin{array}{l}\text { First } \\
\text { vitamin } \\
\text { retest }\end{array}$ & $\begin{array}{l}\text { Increase } \\
\quad \text { or } \\
\text { decrease }\end{array}$ \\
\hline $\begin{array}{c}\text { Mean score of light }+ \\
\text { moderate treated cases } \\
(\mathrm{N}=27)\end{array}$ & $10 \cdot 48$ & 10.04 & . \\
\hline $\begin{array}{c}\text { Mean score of controls } \\
(\mathrm{N}=24)\end{array}$ & $10 \cdot 75$ & $10 \cdot 58$ & \\
\hline
\end{tabular}

There was a slight fall among the controls, but the decrease among the treated was greater by -.27 on our 0 to 20 scale. Increases among the controls might be ascribed to the effects of practice, and decreases to the effects of greater unwillingness or poorer co-operation, assuming that the technique of giving and scoring the tests remained constant throughout. But most such changes were so small as to be attributable merely to chance fluctuations; in only 8 out of 66 comparisons did they reach or exceed 1 point among all the patients. In so far as they are due to practice, unwillingness, and the like, they can be assumed to affect treated and control patients equally, and can, therefore, be neglected since we are concerned only with differences between the treated and controls.

\section{Results}

The results, listed in Table II, show that any changes brought about by the vitamins or hormones were small, that they were often negative-the treated patients improving less or falling off more than the controls - and that they were seldom similar among the light + moderate and among the severe cases. It is of importance to determine which, if any, of the differences are statistically significant. Analysis of variance was first applied in order to show not merely whether there were significant differences between all treated and control patients, but also whether the effects of vitamins differed among light, moderate, and other types of cases. 
Table II.-Total Changes among Treated versus Control Patients

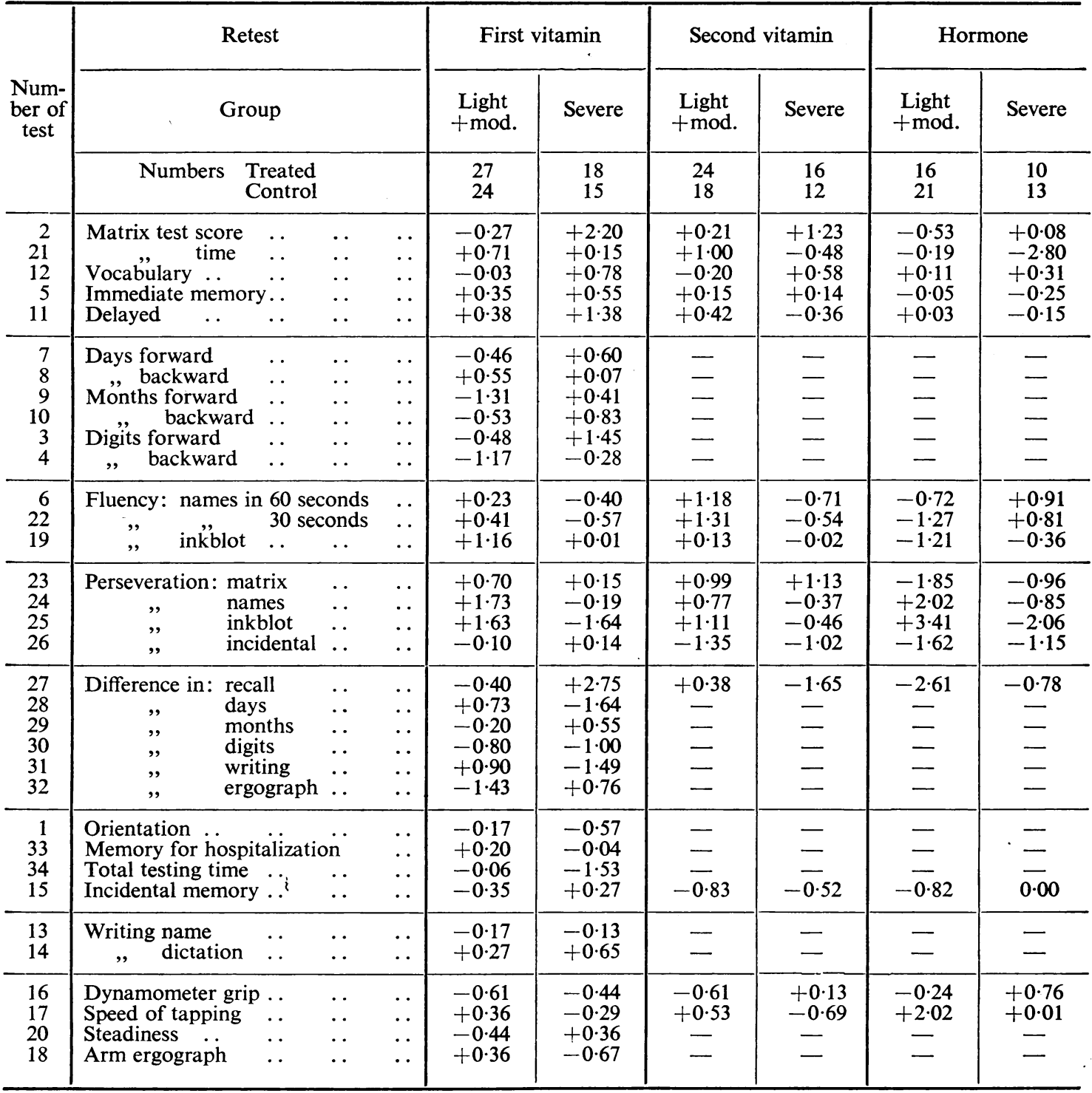

Note.-The numbering of the tests follows that of Eysenck (1945), but their order is rearranged according to similarity of functions tested. Nos. 21 upwards are not described in the article. No. 23 is derived from the number of times any matrix block was put in the same hole and removed. No. 24 is based on numbers of repetitions of the same names (in No. 6), and No. 25 on repetitions of the same inkblot associations (in No. 19). No. 26 includes repetitions in vocabulary, in immediate and delayed recall, and other similar perseverations.

Nos. 27-32 are based on differences between: (27) Nos. 11 and 5; (28) Nos. 7 and 8; (29) Nos. 9 and 10; (30) Nos. 3 and $4 ;(31)$ Nos. 13 and $14 ;$ (32) Initial and final work at ergograph. No. 33 is the correctness of memory for length of hospitalization.

The following is a specimen calculation for the firstvitamin retest on inkblot fluency (No. 19):

\begin{tabular}{|c|c|c|c|c|c|c|}
\hline & \multicolumn{2}{|c|}{ Numbers } & \multicolumn{2}{|c|}{$\Sigma \mathrm{D}$} & \multicolumn{2}{|c|}{$\Sigma \mathrm{D}^{2}$} \\
\hline & Tr. & $\mathrm{Cn}$. & Tr. & Cn. & Tr. & Cn. \\
\hline $\begin{array}{l}\text { Light .. } \\
\text { Moderate } \\
\text { Severe . } \\
\text { Anomalous }\end{array}$ & $\begin{array}{r}7 \\
20 \\
9 \\
8\end{array}$ & $\begin{array}{r}6 \\
18 \\
8 \\
6\end{array}$ & $\begin{array}{l}+16 \\
+21 \\
+9 \\
+7\end{array}$ & $\begin{array}{r}+8 \\
-3 \\
+12 \\
+1\end{array}$ & $\begin{array}{r}44 \\
261 \\
49 \\
71\end{array}$ & $\begin{array}{r}92 \\
171 \\
42 \\
117\end{array}$ \\
\hline All & 44 & 38 & +53 & +18 & 425 & 422 \\
\hline
\end{tabular}

\begin{tabular}{|c|c|c|c|c|}
\hline & $\begin{array}{l}\text { Sum of } \\
\text { squares }\end{array}$ & d.f. & $\begin{array}{l}\text { Mean } \\
\text { square }\end{array}$ & $\underset{\text { ratio }}{\mathrm{F} \text { - }}$ \\
\hline $\begin{array}{c}\text { Variance between } \\
\text { treated and con- } \\
\text { trols } \\
\text { Variance between } \\
\text { clinical groups } \\
\text { Interaction } \\
\text { Residual .. }\end{array}$ & $\begin{array}{r}10.89 \\
21.87 \\
8.84 \\
743.92\end{array}$ & $\begin{array}{r}1 \\
3 \\
3 \\
74\end{array}$ & $\begin{array}{r}10 \cdot 89 \\
7 \cdot 29 \\
2 \cdot 95 \\
10 \cdot 05\end{array}$ & $\begin{array}{c}1.09 \\
0.73 \\
0.30 \\
-\end{array}$ \\
\hline Total variance .. & $785 \cdot 52$ & 81 & 一 & 一 \\
\hline
\end{tabular}


Neither the difference between treated and controls, nor the variations between clinical groups, are significant, since their F-ratios would need to reach 7.0 and 4.0 to achieve a probability of 1 in a 100 , or 4.0 and 2.7 for a probability of 1 in 20 . The results of similar calculation for several of the tests at the first-vitamin phase are shown in Table III.

Table III.-The Significance of Differences OBTAINED AT THE FIRST VITAMIN RETEST

\begin{tabular}{|c|c|c|c|c|}
\hline \multirow{2}{*}{$\begin{array}{l}\text { Num- } \\
\text { ber of } \\
\text { test }\end{array}$} & & \multicolumn{3}{|c|}{ F-ratios } \\
\hline & & $\begin{array}{l}\text { Treated } \\
\text { versus } \\
\text { control }\end{array}$ & $\begin{array}{c}\text { Be- } \\
\text { tween } \\
\text { groups }\end{array}$ & $\begin{array}{l}\text { Inter- } \\
\text { action }\end{array}$ \\
\hline $\begin{array}{r}2 \\
12 \\
5 \\
11 \\
9 \\
4 \\
24 \\
34\end{array}$ & $\begin{array}{ll}\text { Matrix } & . . \\
\text { Vocabulary . . } & \ldots \\
\text { Immediate memory.. } \\
\text { Delayed recall } \\
\text { Months forward } & \text {.. } \\
\text { Digits backward } & \text {. } \\
\text { Perseveration: names } \\
\text { Testing time }\end{array}$ & $\begin{array}{l}1.05 \\
0.52 \\
0.63 \\
1.53 \\
1.75 \\
1.80 \\
1.80 \\
0.88\end{array}$ & $\begin{array}{l}0.57 \\
0.08 \\
1.09 \\
0.46 \\
0.23 \\
0.14 \\
0.84 \\
0.20\end{array}$ & $\begin{array}{l}2.63 \\
0.62 \\
0.67 \\
1.44 \\
1.88 \\
0.88 \\
0.93 \\
0.35\end{array}$ \\
\hline
\end{tabular}

These figures are all below the level of significance also, and we are entitled to conclude that the vitamin treatment had no definite positive or negative effect on the functions measured by any of the tests, among the whole group of our patients. The same conclusion holds for the increased vitamin and for the hormone treatment. The investigation was, of course, designed to throw light on the effects of hormones and vitamins simultaneously, by analysis of variance. But the numbers in the four groups were so small $(13,20,13$, and 14$)$, and their test performances so irregular, that no such analyses were worth carrying out. (F ratios of less than 1.0 are quoted in order to indicate that between group or interaction variances were smaller than residual variance.) Nevertheless there were indications that certain functions were favourably affected in some types of patients, others in other types. Unfortunately when the types or sub-groups were considered separately, they became too small even for the rather larger positive differences to achieve significance. In particular there seemed to be a distinction between the light +moderate cases on the one hand, and the severe + "anomalous" on the other. Table II, therefore, lists the results for these two major sub-groups separately.

For determining the significance of the differences between means, quoted in Table II, "Student's" method for small samples was employed, and the values of " $t$ " and their probabilities for all the bigger differences are shown in Table IV. While no single difference reached the 0.01 level of significance,

Table IV.-Significance of Bigger Differences in Means

\begin{tabular}{|c|c|c|c|c|c|c|c|c|c|}
\hline $\begin{array}{c}\text { Num- } \\
\text { ber of } \\
\text { tests }\end{array}$ & Test & & & Patients & Retest & $\begin{array}{l}\text { Difference } \\
\text { in means }\end{array}$ & $t$ & d.f. & $\mathbf{P}$ \\
\hline $\begin{array}{r}2 \\
21 \\
11 \\
9 \\
3 \\
6 \\
22 \\
19 \\
23 \\
24 \\
25\end{array}$ & 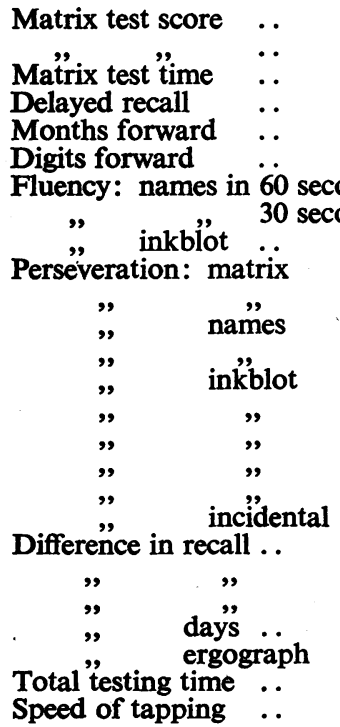 & $\begin{array}{l}\because \\
\because \\
\because \\
\because \\
\text { onds } \\
\text { onds } \\
. \\
\because \\
\because \\
\because \\
\because \\
\because \\
\because \\
\because \\
\because \\
\because \\
\because \\
\because \\
\because \\
.\end{array}$ & $\begin{array}{l}. \\
\because \\
\because \\
\because \\
\because \\
\because \\
\because \\
\because \\
\because \\
\because \\
\because \\
\because \\
\because \\
\because \\
\because \\
\because \\
\because \\
\because \\
\because \\
\because\end{array}$ & $\begin{array}{l}\text { SA } \\
\text { SA } \\
\text { SA } \\
\text { SA } \\
\text { LM } \\
\text { SA } \\
\text { LM } \\
\text { LM } \\
\text { LM } \\
\text { SA } \\
\text { LM } \\
\text { LM } \\
\text { LM } \\
\text { LM } \\
\text { SA } \\
\text { LM } \\
\text { LM } \\
\text { SA } \\
\text { LM } \\
\text { SA } \\
\text { SA } \\
\text { LM } \\
\text { SA } \\
\text { LM } \\
\text { SA } \\
\text { LM }\end{array}$ & $\begin{array}{l}\mathbf{F V} \\
\text { SV } \\
\mathbf{H} \\
\mathbf{F V} \\
\mathbf{F V} \\
\mathbf{F V} \\
\mathbf{S V} \\
\mathbf{S V} \\
\mathbf{F V} \\
\mathbf{S V} \\
\mathbf{H} \\
\mathbf{F V} \\
\mathbf{H} \\
\mathbf{F V} \\
\mathbf{F V} \\
\mathbf{S V} \\
\mathbf{H} \\
\mathbf{H} \\
\mathbf{S V} \\
\mathbf{F V} \\
\mathbf{S V} \\
\mathbf{H} \\
\mathbf{F V} \\
\mathbf{F V} \\
\mathbf{F V} \\
\mathbf{H}\end{array}$ & $\begin{array}{l}+2.20 \\
+1.23 \\
-2.80 \\
+1.38 \\
-1.31 \\
+1.45 \\
+1.18 \\
+1.31 \\
+1.16 \\
+1.13 \\
+1.85 \\
+1.73 \\
+2.02 \\
+1.63 \\
+1.64 \\
+1.11 \\
+3.41 \\
-2.06 \\
-1.35 \\
+2.75 \\
-1.65 \\
-2.61 \\
-1.64 \\
-1.43 \\
-1.53 \\
+2.02\end{array}$ & $\begin{array}{l}1.97 \\
0.91 \\
2.09 \\
1.51 \\
2.01 \\
1.26 \\
2.07 \\
2.15 \\
1.27 \\
1.00 \\
1.78 \\
1.94 \\
1.93 \\
1.41 \\
1.06 \\
0.96 \\
2.36 \\
1.14 \\
0.93 \\
2.37 \\
0.95 \\
1.65 \\
1.36 \\
0.94 \\
1.28 \\
1.95\end{array}$ & $\begin{array}{l}30 \\
26 \\
19 \\
31 \\
49 \\
31 \\
40 \\
40 \\
49 \\
26 \\
34 \\
49 \\
35 \\
49 \\
29 \\
39 \\
34 \\
20 \\
40 \\
30 \\
25 \\
33 \\
31 \\
49 \\
31 \\
35\end{array}$ & $\begin{array}{l}0.06 \\
0.4 \\
0.05 \\
0.2 \\
0.05 \\
0.3 \\
0.05 \\
0.04 \\
0.3 \\
0.3 \\
0.1 \\
0.05 \\
0.05 \\
0.2 \\
0.3 \\
0.3 \\
0.03 \\
0.3 \\
0.4 \\
0.03 \\
0.4 \\
0.1 \\
0.2 \\
0.4 \\
0.2 \\
0.05\end{array}$ \\
\hline $\begin{array}{l}2 \\
7 \\
6\end{array}$ & 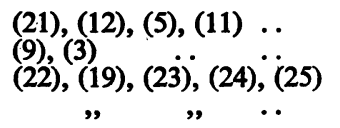 & $\begin{array}{l}\cdots \\
\ddot{*} \\
\cdots\end{array}$ & $\begin{array}{l}. \\
\cdots \\
\cdots \\
.\end{array}$ & $\begin{array}{l}\text { SA } \\
\text { SA } \\
\text { LM } \\
\text { LM }\end{array}$ & $\begin{array}{l}\text { FV } \\
\text { FV } \\
\text { FV } \\
\text { SV }\end{array}$ & $\bar{z}$ & $\begin{array}{l}1.95 \\
1.38 \\
2.85 \\
1.95\end{array}$ & $\begin{array}{r}30 \\
31 \\
49 \\
39\end{array}$ & $\begin{array}{l}0.06 \\
0.2 \\
0.005 \\
0.05\end{array}$ \\
\hline
\end{tabular}

LM and SA refer to the light +moderate and severe +anomalous cases. FV, SV, and $\mathrm{H}$ refer to the first and second vitamin and hormone retests, respectively. $P$ is the probability of the difference. 
eight positive differences and two negative ones reached the 0.03 to 0.06 level. Though it is conceivable that chance fluctuations might have produced this result, it seems more likely that we have obtained evidence of the vitamins or hormones producing small favourable effects on certain psychological functions in certain types of patients. This conclusion is strengthened by the observation that, with the vitamin retests at least, the improvements appeared to be localized among particular types or groups of tests, not scattered at random. Thus, with the light + moderate first-vitamin retest, all the fluency tests and all the perseveration ones except the very unreliable No. 26 gave positive differences. But the general intelligence and memory tests (matrix, vocabulary, etc.), the speed tests (days, etc. forward and backward), and the psychomotor tests all yielded rather smaller differences, more of which were negative than positive. Adding the scores of the six fluency and perseveration tests gave a difference between light + moderate treated and control patients which would be accepted as fully significant statistically $(P=0.005)$. At the second vitamin retest the differences on these same tests were positive, though their significance had fallen $(P=0 \cdot 05)$. At the hormone retest, the light + moderate patients did well on names and inkblot perseveration, but not on matrix perseveration, nor on the fluency tests. Thus there was no longer any indication of a general psychological function of high fluency with low perseveration being improved by treatment. (It will be remembered that positive differences, representing improvements, correspond to increased fluency and to decreased perseveration.) In the severe+ "anomalous" group of patients neither vitamins nor hormones had any positive effect on fluency and perseveration tests; indeed rather the reverse. But the five general intelligence tests at the head of the list showed positive results at the first vitamin retest, as also did five of the six speed tests. Although the statistical significance of these differences is poor, $\mathbf{P}=0.06$ for the five summed general tests, and $\mathrm{P}=\mathbf{0 . 2}$ for days, months, and digits forward, yet it is possible that general intellectual ability was slightly improved among more extreme cases of senility by vitamin treatment. Both the second retest, however, and the hormone test failed to show such an effect. The psychomotor tests and the miscellaneous ones in the bottom half of Table II appeared to be as slightly and as irregularly affected in this group as among the lights + moderates.

It is interesting that the most promising results were obtained with tests which could be regarded as measuring well-recognized mental factors. Previous researches with fluency or $f$-tests and perseveration or $p$-tests have revealed marked differences between different psychopathological groups (cf. Stephenson, 1934). Again, the tests which showed some improvement among the severe cases were tests of $g$, most of them, in fact, occurring in the Stanford-Binet scale for general intelligence. A few other tests yielded considerable differences between our treated and control patients, for example difference in recall at the first vitamin retest of severe cases, and tapping at the hormone retest of light + moderate cases. But single results of this kind not backed by results from other similar tests were almost impossible to interpret, and might well have been chance ones. Many promising attempts to measure mental deterioration have been made by contrasting abstract reasoning tests, or tests of mental speed, with such tests as vocabulary and information, which depend more on the undeteriorated intellectual level (cf. Brody, 1942). Tests Nos. 2731 in our battery all contrasted more complex mental activities with simpler, rote, activities, but failed to yield any consistent indications of improvements; nor were differences between any of the tests and vocabulary (No. 12) worth considering. It was hoped to include in the investigation not only psychological tests, but also observations of more general qualities, such as alertness and co-operativeness, which might be improved by treatment. However, there were difficulties in arriving at a satisfactory rating scale, and such results as were obtained did not approximate to statistical significance; hence they are omitted here. The psychologist who applied the tests was intentionally kept in ignorance of the identity of the treated patients, in order to prevent her expectations affecting the patients' performances in any way. Thus it is not possible to mention even any general impressions that she might have obtained of differences brought about by treatment.

\section{Discussion}

The only positive psychological findings of this investigation are that moderate doses of vitamins may improve general mental ability or $g$-factor among severe cases of senility, and may produce some increase in fluency and decrease in perseveration among light and moderate cases. Even these changes, amounting to about 10 per cent. (i.e. an average of roughly 1 point on a 0 to 20 point scale) are so much on the borderline of statistical significance that they cannot be regarded as proven without further evidence. At a later testing, after increased doses of vitamins, the effects were reduced instead of becoming more prominent, and no clearcut effects of androgenous hormones could be discovered. Moreover, psychomotor tests, similar to those used by Stephenson and Korenchevsky, and other miscellaneous tests failed to show positiveresults throughout. Several factors may help to account for these disappointing conclusions. First, the total number of patients was small, and fell still further in the course of the investigation. If, as our results suggest, vitamins and hormones have different effects on different types of patients, it would be necessary to have at least a hundred patients of each type before we could hope to collect adequate evidence. We do not know how many types should be distinguished; certainly the two major subgroups investigated above included many very heterogeneous cases. Secondly, the fact that the patients' diet was already adequate in vitamins very 
probably provides the explanation of the difference between our results and those of Stephenson and Korenchevsky with psychomotor tests. Thirdly, several of the tests, particularly those denoted above as "miscellaneous", are likely to be low in reliability. The greater the unreliability, the more widespread and haphazard will be the changes of score on retest, and these changes will tend to mask any general trend produced by vitamin or other treatment. Fourthly, in the writers' opinion the system of repeated retesting is an undesirable one. The patients' attitudes towards, and memory of, the tests are likely to have altered so much during the two years' investigation that no valid and reliable comparisons could be drawn between the results of the fourth or fifth testing and the first two. This may explain why the first vitamin retest appeared to give moderately promising results, but the later retests did not. A much better plan would have been that normally adopted in educational investigations which involve retesting, namely, to have had parallel forms, A and B, of each test and to have tested each patient only twice in all (half taking Form A first, Form B second, and half the reverse). That is to say, different groups of patients should be used for investigating each type of treatment. Admittedly this would make investigations of senility extremely complex and laborious, but that is inevitable in studying human individuals, with memories, interests, and sentiments of their own.

\section{Summary}

Small groups of male senile patients were treated: (i) with small doses of vitamins B and C; (ii) with increased doses; (iii) with androgenous hormones. The patients, together with similar numbers of untreated controls, were tested individually with a large battery of mental and psychomotor tests before treatment and during each phase of treatment.

No evidence was obtained of any general improvement in intellectual efficiency or psychomotor capacities as a result of the treatment. There were slight indications of an improvement on general intelligence $(g)$ tests among the more severe cases with vitamin treatment; and among the light and moderate cases the same treatment produced an increase in fluency and a decrease in perseverative tendencies ( $f$ and $p$ factors).

Though these improvements amounted to about 10 per cent., they were of doubtful statistical significance and require confirmation with larger and more homogeneous groups of patients. Neither the psychomotor tests nor tests of intellectual deterioration were affected in any consistent manner. The increased vitamin treatment did not yield any more positive results, and the hormone treatment was apparently quite ineffective.

The lack of any clear-cut effects of treatment may have been due partly to the fact that the patients were already on a diet adequate in vitamins, and partly to the unreliability of psychological tests when repeated too frequently over too long a period.

The laboratory and the research on ageing were financed from grants to the Club for Research on Ageing by Lord Nuffield and the Nuffield Foundation, to whom the Club and the authors express their thanks. They wish further to thank the London County Council, and Dr. P. Turnbull, Medical Superintendent of the Tooting Bec Hospital, for all the facilities given at the hospital; also the Government Chemical Laboratory at Teddington, and in particular Dr. A. Thaysen, for supplies of yeast; and Roche Products, Ltd., for supplies of vitamins $B$ and $C$.

\section{REFERENCES}

Brody, M. B. (1942). Brit. J. med. Psychol., 19, 215. Eysenck, M. D. (1945). Journal of Neurology, Neurosurgery and Psychiatry, 8, 15.

Halstead, H. (1943). J. ment. Sci., 89, 363.

(1944). Ibid., 90, 720.

Korenchevsky, V. (1942). Ann. Eugen., 11, 314.

Richter, D. et al. (1946). “ Ageing and Nutrition." (In the press.)

Stephenson, W. et al. (1934). Brit. J. med. Psychol., 14, 101.

- Penton, C., and Korenchevsky, V. (1941). Brit. med. J., 2, 839. 